\title{
In Situ Formation of C-Glycosides \\ During Electrospray Ionization Tandem \\ Mass Spectrometry of a Series \\ of Synthetic Amphiphilic Cholesteryl \\ Polyethoxy Neoglycolipids \\ Containing $N$-Acetyl-D-Glucosamine
}

\author{
Joseph Banoub* \\ Special Projects, Science Branch, Department of Fisheries and Oceans, St. John's, Newfoundland, Canada
}

Paul Boullanger and Dominique Lafont

Laboratoire de Chimie Organique 2, Université Claude Bernard, Villeurbanne, France

\author{
Alejandro Cohen, Anas El Aneed, and Elizabeth Rowlands \\ Biochemistry Department, Memorial University of Newfoundland, St. John's, Newfoundland, Canada
}

\begin{abstract}
In this communication, the structural analysis of six synthetic O-Linked amphiphilic cholesteryl polyethoxy neoglycolipids containing $N$-acetyl-D-glucosamine was performed by electrospray ionization mass spectrometry in the positive ion mode, with a QqTOF-MS/MS hybrid instrument. The MS/MS analyses provided evidence for the "in situ" formation, in the collision cell of the tandem mass spectrometer, of an unexpected and unique [C-glycoside $]^{+}$product ion, resulting from an ion-molecule reaction between the $\mathrm{N}$-acetyl-D-glucosamine oxonium ion and the neutral cholesta-3,5-diene molecule. Quasi $\mathrm{MS}^{3}$ analysis of this ion resulted in the dissociation of the precursor [C-glycoside] ${ }^{+}$ion, which produced the expected third generation $\mathrm{N}$-acetyl-D-glucosamine oxonium and the protonated cholesta-3,5-diene product ions. (J Am Soc Mass Spectrom 2005, 16, 565-570) (C) 2005 American Society for Mass Spectrometry
\end{abstract}

$\mathrm{T}$ The structural diversity of complex carbohydrates of cell surface membranes has been much more appreciated over the last two decades, due to the vast improvement in analytical techniques.

We have synthesized a series of amphiphilic neoglycolipid cholesteryl derivatives (see Scheme 1), in which the cholesterol and carbohydrate ( $N$-acetyl-D-glucosamine) moieties were attached by means of a polyethoxy variable spacer [1, 2]. Synthetic neoglycolipids have been successfully incorporated into liposomal formulations to prolong their half lives as alternative to pegylated liposomes (PEG-liposomes) [3, 4]. More recently, novel series of neoglycolipids bearing various sugar monomers or oligomers have been evaluated as stabilizing agents for cationic liposomes [5] which are one of the most important nonviral gene carriers used in cancer gene therapy [6]. In

Published online February 23, 2005

Address reprint requests to Dr. J. H. Banoub, Northwest Atlantic Fisheries Center, Fisheries and Oceans Canada, Memorial University of Newfoundland, P.O. Box 5667, St. John's, Newfoundland A1C 5S7, Canada. E-mail: Banoubjo@dfo-mpo.gc.ca

* Also at the Biochemistry Department, Memorial University of Newfoundland, St. John's, Newfoundland, Canada. this study, neoglycolipid-stabilized liposomes were superior to PEG-stabilized liposomes in terms of gene transfer efficiency [5].

In the present communication, we report the "in situ" formation, both in the collision cell and the ESI interface of the tandem mass spectrometer, of an unexpected and unique [C-glycoside $]^{+}$product ion, resulting from an ion-molecule reaction between the $\mathrm{N}$-acetyl-D-glucosamine oxonium ion and the neutral cholesta-3,5-diene molecule. We also propose the fragmentation routes of these synthetic amphiphilic cholesteryl polyethoxy neoglycolipids by electrospray ionization mass spectrometry with a QqTOF-MS hybrid instrument. The low-energy collision induced dissociation (CID) tandem mass spectrometric analyses are also described.

\section{Experimental}

\section{Materials}

The synthesis of the neoglycolipid derivatives was performed as reported $[8,9]$. The molecular structures of these derivatives are shown in Scheme 1. 


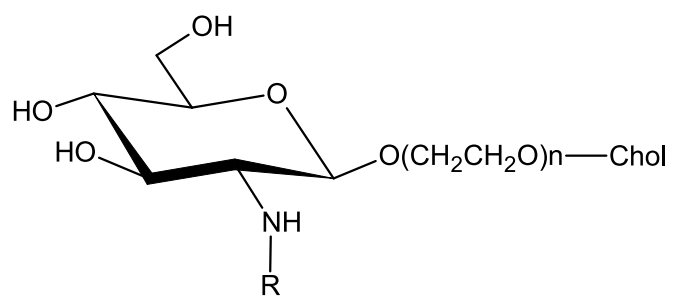

\begin{tabular}{|c|c|c|c|c|}
\hline $\mathrm{R}$ & 1 & 2 & 3 & 4 \\
\hline $\mathrm{H}$ & & Chol-2' & & \\
\hline $\mathrm{COCH}_{3}$ & Chol-1 & Chol-2 & Chol-3 & Chol-4 \\
\hline $\mathrm{COCD}_{3}$ & & & Chol-3' & \\
\hline
\end{tabular}

Scheme 1. Synthetic amphiphilic neoglycolipid cholesteryl derivatives.

\section{Electrospray Quadrupole Orthogonal}

Time-of-Flight Mass Spectrometry

Mass spectra of the neoglycolipid derivatives were acquired in the positive ion mode. All experiments were performed with an Applied Biosystems, API QSTAR XL MS/MS (California, USA) quadrupole orthogonal timeof-flight (QqToF-MS/MS) hybrid tandem mass spectrometer. Samples were dissolved in methanol for ESI with a catalytic amount of formic acid $(2 \mu \mathrm{L}$ of $1 \mathrm{~N}$ formic acid) to achieve a concentration of $1 \mu \mathrm{mol} / \mu \mathrm{L}$. Aliquots $(3 \mu \mathrm{L})$ were infused into the mass spectrometer with an integrated Harvard syringe pump (Quebec, Canada) at a rate of $10 \mu \mathrm{L} / \mathrm{min}$ using the Turbo Ionspray source, operated at $5.5 \mathrm{kV}$ at a temperature of 80 to $100{ }^{\circ} \mathrm{C}$. Formic acid was added to increase the formation of the $[\mathrm{M}+\mathrm{H}]^{+}$protonated molecules.

\section{Results and Discussion}

\section{ESI-QqTOF Mass Spectrometry of the Synthetic Neoglycolipids}

The neoglycolipds GlcNAc-Chol-1, GlcNAc-Chol-2, GlcNH2-Chol-2', GlcNAc-Chol-3, GlcNHCOCD ${ }_{3}$-Chol3', and GlcNAc-Chol-4 (Scheme 1) were analyzed by electrospray mass spectrometry in the positive ion mode. The ESI-QqTOF-MS were measured with different declustering potentials (DP values 80 to $150 \mathrm{~V}$ ) and showed, in all cases, abundant protonated molecules and the corresponding sodiated adducts, which were consistent ${ }^{\circ}$ with $^{\circ}$ the ${ }^{\circ}$ expected $^{\circ}$ molecular $^{\circ}$ formulas ${ }^{\circ}$ (Figure ${ }^{\circ} 1$ a shows only the ESI-MS of GlcNAc-Chol-3). The electrospray mass spectra of this series of synthetic neoglycolipids were recorded using a DP of $130 \mathrm{~V}$ and the characteristic ions, with their calculated and observed masses and relative intensities (RA\%), are presented in Table $^{\circ} 1^{\circ}$ (only ${ }^{\circ}$ neoglycolipids $2,{ }^{\circ} 2^{\prime}, 3^{\circ}$ and $^{\circ} 3^{\prime}{ }^{\circ}$ are ${ }^{\circ}$ shown). The ESI-MS of this series of amphiphilic glycolipids showed the different expected values for the $[\mathrm{M}+\mathrm{H}]^{+}$ and $\left[\mathrm{M}+\mathrm{Na}^{+}\right.$of the protonated and sodiated molecules. We noticed the formation of the series of oxonium ions at $\mathrm{m} / \mathrm{z} 204.0871$ for [GlcNAc] $^{+}, \mathrm{m} / \mathrm{z} 162.0766$ for $\left[\mathrm{GlcNH}_{2}\right]^{+}$, and $\mathrm{m} / \mathrm{z} 207.1054$ for $\left[\mathrm{GlcNHCOCD}_{3}\right]^{+}$ which, according to our previous experience, are very stable $^{\circ}$ in $^{\circ}$ solution ${ }^{\circ}[7-9]^{\circ}$ In $^{\circ}$ addition, ${ }^{\circ}$ we $^{\circ}$ noted $^{\circ}$ the [cholestene] $^{+}$ion at $\mathrm{m} / \mathrm{z} 369.3522$, formed by heterolytic cleavage of the O-spacer arm-cholesteryl moiety. The series of remaining fragment ions and elimination products formed in the ESI'interface are identified in Table 1. It should be noted that the $\mathrm{m} / \mathrm{z}$ value of the [(GlcNAcspacer-OH) $+\mathrm{H}^{+}$fragment ion, as expected, will vary depending on the length of the polyethoxy spacer chain.

We noted an unexpected singly charged ion at $\mathrm{m} / \mathrm{z}$ 572.4314 , which could not be rationally explained by the expected ESI-MS fragmentation of these amphiphilic molecules. Interestingly, the structural identity of this ion was compatible with that of a C-glycoside species, the formation of which was highly unlikely under the experimental conditions. This [C-glycoside] ${ }^{+}$ion at $\mathrm{m} / \mathrm{z}$ 572.4314 was present in all of the ESI-MS of GlcNAcChol-1 to GlcNAc-Chol-4. Similarly, we also noticed the formation of the [C-glycoside] ${ }^{+}$ions at $m / z 530.4209$ and 575.4497, for $\mathrm{GlcNH}_{2}$-Chol-2' and GlcNHCOCD ${ }_{3}$-Chol$3^{\prime}$, respectively. The intensities of these ions increased as the DP was increased to a value of $150 \mathrm{~V}$, indicating that they were formed in the interface between the ionization source and the analyzer. It is noteworthy to mention that the intensity of these [C-glycoside] ions did not increase when more acid was added prior to ESI analyses. This C-glycoside formation was not observed during analysis by negative ion ESI-MS. The mechanism of formation of the [C-glycoside] $]^{+}$ion at $m / z 572.4314$ is illustrated in the following sections. 

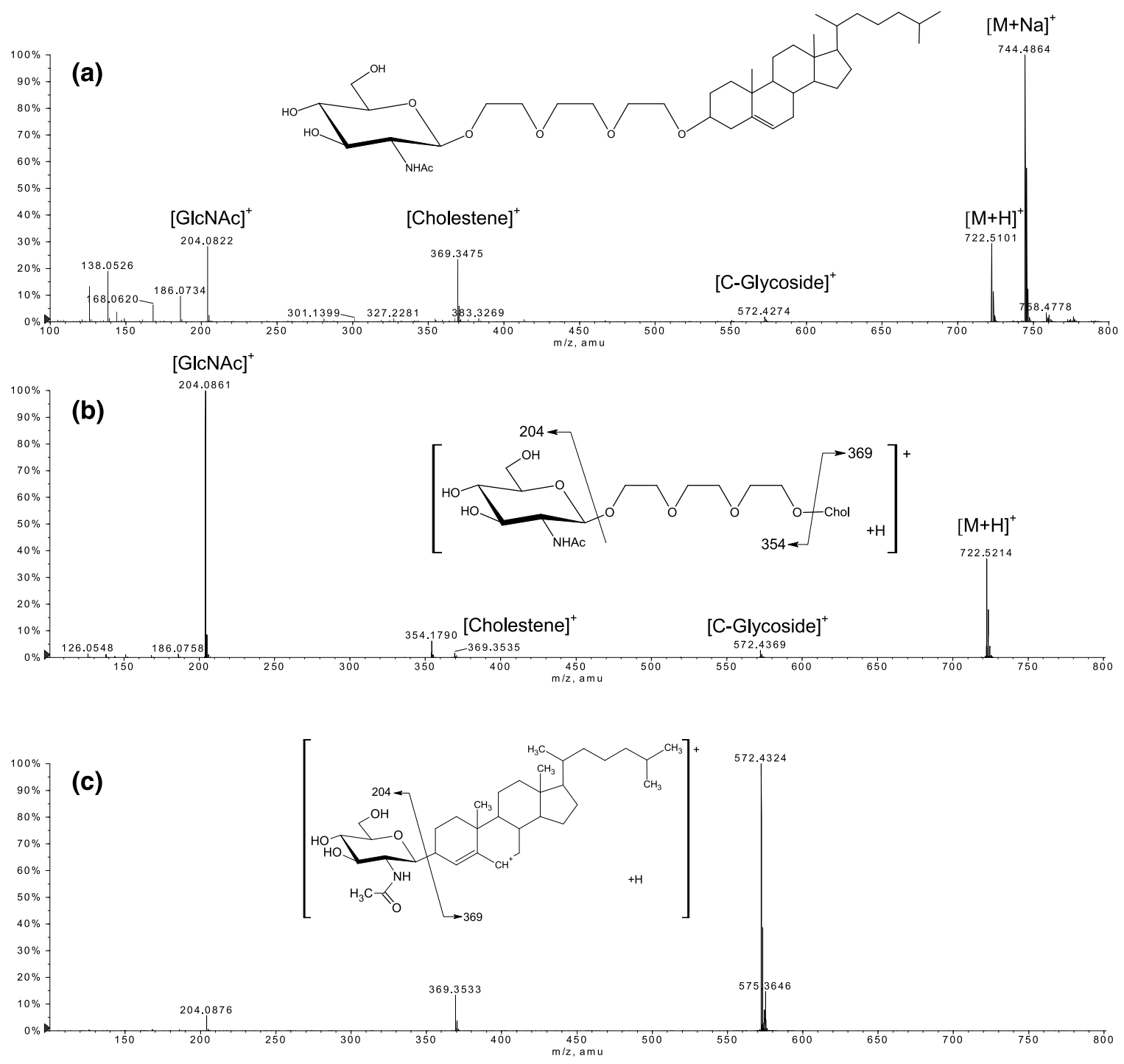

Figure 1. ESI-MS of GlcNAc-Chol-3 (a), low-energy CID-MS/MS spectra of the precursors $[\mathrm{M}+\mathrm{H}]^{+}$ protonated GlcNAc-Chol-3 (b), and second generation product ion scans of the [C-glycosides] ${ }^{+}$at $m / z$ 572 (c).

Low-energy CID-MS/MS of the Precursor

Protonated Molecules of the Amphiphilic

\section{Neoglycolipids}

Low-energy MS/MS analyses were conducted to rationalize the pathways leading to the various fragmentations observed in the conventional electrospray mass spectra. Precursor protonated molecules $[\mathrm{M}+\mathrm{H}]^{+}$ obtained from this series of the neoglycolipids were selected for the recording of the CID-MS/MS using a $\mathrm{CE}=15 \mathrm{eV}$ and $\mathrm{DP}=130 \mathrm{~V}$. The CID-MS/MS of the protonated molecule at $\mathrm{m} / \mathrm{z} 634.4682$ (calculated for $\mathrm{C}_{37} \mathrm{H}_{64} \mathrm{NO}_{7}=634.4683$ ) obtained from GlcNAc-Chol-1 suggested the formation of the cholesteryl cation, which carries the positive charge on C-3' assigned as the [cholestene] ${ }^{+}$product ion at $\mathrm{m} / \mathrm{z} 369.3586$ (calculated for $\left.\mathrm{C}_{27} \mathrm{H}_{45}=369.3522\right)$. The $[(\mathrm{GlcNAc} \text {-spacer-OH })+\mathrm{H}]^{+}$at $\mathrm{m} / \mathrm{z} 266.1280$ and the [GlcNAc] $^{+}$at $\mathrm{m} / \mathrm{z} 204.0894$ were also noted. It is apparent that these three product ions result from cleavages of intact covalent bonds of the precursor protonated neoglycolipid molecules. In addition, the presence of the product ions obtained from losses of one and two molecules of water from the [GlcNAc] $^{+}$ion at $\mathrm{m} / \mathrm{z} 204.0894$ was also observed respectively at $\mathrm{m} / \mathrm{z} 186.0782$ and 168.0688 . The product ions [GlcNAc- $\left.2 \mathrm{H}_{2} \mathrm{O}-\mathrm{CO}\right]^{+}$and [GlcNAc- $\left.2 \mathrm{H}_{2} \mathrm{O}-\mathrm{CH}_{2} \mathrm{CO}\right]^{+}$, respectively, at $\mathrm{m} / \mathrm{z} 138.0574$ and 126.0567 were also noted. Once more, we witnessed the formation of the [Cglycoside $]^{+}$product ion at $\mathrm{m} / \mathrm{z} 572.4382$.

The product ion scans of the precursor protonated molecules $[\mathrm{M}+\mathrm{H}]^{+}$at $m / z 678.4952,636.4846,722.5209$, and 725.5390 selected from (GlcNAc-Chol-2), $\left(\mathrm{GlcNH}_{2}-\right.$ Chol-2'), (GlcNAc-Chol-3), and (GlcNHCOCD ${ }_{3}$-Chol$\left.3^{\prime}\right)$, respectively, were also obtained (Figure $1 \mathrm{~b}$, shows only the MS/MS of GlcNAc-Chol-3). Again, we noticed 
Table 1. List of characteristic calculated and observed peaks observed (Relative Abundance: RA\%) during the ESI-QqTOF analysis of the synthetic neoglycolipids

\begin{tabular}{|c|c|c|c|c|c|c|c|c|}
\hline \multirow[b]{2}{*}{ Characteristic ions } & \multicolumn{2}{|c|}{ GlcNAc-Chol-2 } & \multicolumn{2}{|c|}{$\mathrm{GlcNH}_{2}-\mathrm{Chol}^{\prime} 2^{\prime}$} & \multicolumn{2}{|c|}{ GlcNAc-Chol-3 } & \multicolumn{2}{|c|}{$\mathrm{GlcNHCOCD}_{3}-{\mathrm{Chol}-3^{\prime}}^{\prime}$} \\
\hline & Calc. & Obs. $\%$ & Calc. & Obs. \% & Calc. & Obs. \% & Calc. & Obs. \% \\
\hline \multirow[t]{3}{*}[\mathrm{M}+\mathrm{Na}]{$^{+}$} & 700.476 & 700.473 & \multicolumn{2}{|c|}{-} & 744.503 & 744.504 & 747.521 & 747.518 \\
\hline & & 100 & & & & 92 & & 100 \\
\hline & \multicolumn{2}{|c|}{$\mathrm{C}_{39} \mathrm{H}_{67} \mathrm{NaNO}_{8}$} & & & $\mathrm{C}_{41} \mathrm{H}_{7 \mathrm{C}}$ & $\mathrm{aNO}_{9}$ & $\mathrm{C}_{41} \mathrm{H}_{67} \mathrm{~L}$ & $\mathrm{NO}_{9}$ \\
\hline \multirow[t]{3}{*}[\mathrm{M}+\mathrm{H}]{$^{+}$} & 678.495 & 678.495 & 636.484 & 636.485 & 722.521 & 722.521 & 725.539 & 725.539 \\
\hline & \multirow{2}{*}{\multicolumn{2}{|c|}{$\mathrm{C}_{39} \mathrm{H}_{68} \mathrm{NO}_{8}$}} & & 100 & & 36 & & 46 \\
\hline & & & \multicolumn{2}{|c|}{$\mathrm{C}_{37} \mathrm{H}_{66} \mathrm{NO}_{7}$} & \multicolumn{2}{|c|}{$\mathrm{C}_{41} \mathrm{H}_{71} \mathrm{NO}_{9}$} & \multicolumn{2}{|c|}{$\mathrm{C}_{41} \mathrm{H}_{68} \mathrm{D}_{3} \mathrm{NO}_{9}$} \\
\hline \multirow[t]{3}{*}[\text{C-glycoside}]{$^{+}$} & 572.431 & 572.438 & 530.421 & 530.427 & 572.431 & 772.432 & 575.450 & 575.453 \\
\hline & & 2 & & 0.5 & & 4 & & 4 \\
\hline & \multicolumn{2}{|c|}{$\mathrm{C}_{35} \mathrm{H}_{58} \mathrm{NO}_{5}$} & \multicolumn{2}{|c|}{$\mathrm{C}_{33} \mathrm{H}_{55} \mathrm{NO}_{4}$} & \multicolumn{2}{|c|}{$\mathrm{C}_{35} \mathrm{H}_{58} \mathrm{NO}_{5}$} & \multicolumn{2}{|c|}{$\mathrm{C}_{35} \mathrm{H}_{55} \mathrm{D}_{3} \mathrm{NO}_{5}$} \\
\hline \multirow[t]{2}{*}{ 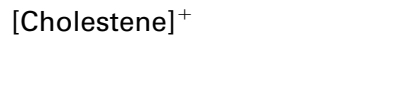 } & 369.352 & $\begin{array}{c}369.353 \\
38\end{array}$ & 369.352 & $\begin{array}{c}369.355 \\
31\end{array}$ & 369.352 & $\begin{array}{l}369.353 \\
50\end{array}$ & 369.352 & $\begin{array}{c}369.353 \\
46\end{array}$ \\
\hline & \multicolumn{2}{|c|}{$\mathrm{C}_{27} \mathrm{H}_{45}$} & \multicolumn{2}{|c|}{$\mathrm{C}_{27} \mathrm{H}_{45}$} & \multicolumn{2}{|c|}{$\mathrm{C}_{27} \mathrm{H}_{45}$} & \multicolumn{2}{|c|}{$\mathrm{C}_{27} \mathrm{H}_{45}$} \\
\hline \multirow[t]{2}{*}[(\mathrm{GlcNHR}-\mathrm{Spacer}-\mathrm{OH})+\mathrm{H}]{$^{+}$} & 310.150 & $\begin{array}{c}310.154 \\
3\end{array}$ & 268.140 & $\begin{array}{c}268.143 \\
1\end{array}$ & 354.176 & $\begin{array}{c}354.176 \\
5\end{array}$ & 357.195 & $\begin{array}{c}357.198 \\
1.5\end{array}$ \\
\hline & \multicolumn{2}{|c|}{$\mathrm{C}_{12} \mathrm{H}_{24} \mathrm{NO}_{8}$} & \multicolumn{2}{|c|}{$\mathrm{C}_{10} \mathrm{H}_{22} \mathrm{NO}_{7}$} & \multicolumn{2}{|c|}{$\mathrm{C}_{14} \mathrm{H}_{28} \mathrm{NO}_{9}$} & \multicolumn{2}{|c|}{$\mathrm{C}_{14} \mathrm{H}_{25} \mathrm{D}_{3} \mathrm{NO}_{9}$} \\
\hline \multirow[t]{3}{*}{ [GlcNHR] $^{+}$} & 204.087 & 204.087 & 162.077 & 162.076 & 204.087 & 204.076 & 207.105 & 207.104 \\
\hline & & & & 3.5 & & 100 & & 50 \\
\hline & \multicolumn{2}{|c|}{$\mathrm{C}_{8} \mathrm{H}_{14} \mathrm{NO}_{5}$} & $\mathrm{C}_{6} \mathrm{H}$ & $\mathrm{NO}_{4}$ & $\mathrm{C}_{8} \mathrm{H}$ & $\mathrm{NO}_{5}$ & $\mathrm{C}_{8} \mathrm{H}_{11}$ & \\
\hline$\left[\mathrm{GlcNHR}-\mathrm{H}_{2} \mathrm{O}\right]^{+}$ & 186.077 & 186.078 & 144.066 & 144.067 & 186.077 & 186.076 & 189.095 & 189.095 \\
\hline & & 12 & & 2 & & 35 & & 18 \\
\hline & $\mathrm{C}_{8} \mathrm{H}$ & $\mathrm{NO}_{4}$ & $\mathrm{C}_{6} \mathrm{H}$ & $\mathrm{NO}_{3}$ & $\mathrm{C}_{8} \mathrm{H}$ & $\mathrm{NO}_{4}$ & $\mathrm{C}_{8} \mathrm{H}_{9}$ & \\
\hline$\left[\mathrm{GlcNHR}-2 \mathrm{H}_{2} \mathrm{O}\right]^{+}$ & 168.066 & 168.066 & 126.056 & 126.054 & 168.066 & 168.064 & 171.084 & 171.084 \\
\hline & & 8 & & 1 & & 24 & & 11 \\
\hline & $\mathrm{C}_{8} \mathrm{H}$ & $\mathrm{NO}_{3}$ & $\mathrm{C}_{6} \mathrm{r}$ & $\mathrm{JO}_{2}$ & $\mathrm{C}_{8} \mathrm{H}$ & $\mathrm{NO}_{3}$ & $\mathrm{C}_{8} \mathrm{H}_{7}$ & \\
\hline$\left[\mathrm{GlcNHR}-2 \mathrm{H}_{2} \mathrm{O}-\mathrm{CO}\right]^{+}$ & 138.056 & 138.056 & & & 138.056 & 138.055 & 141.074 & 141.074 \\
\hline & & 29 & & & & 70.5 & & 33 \\
\hline & $\mathrm{C}_{7} \mathrm{H}$ & $\mathrm{NO}_{2}$ & & & $\mathrm{C}_{7} \mathrm{H}$ & $\mathrm{NO}_{2}$ & $\mathrm{C}_{7} \mathrm{H}_{5}$ & \\
\hline$\left[\mathrm{GlcNHR}-2 \mathrm{H}_{2} \mathrm{O}-\mathrm{CH}_{2} \mathrm{CO}\right]^{+}$ & 126.056 & 126.055 & & & 126.056 & 126.054 & 129.074 & 129.073 \\
\hline & & 19 & & & & 44 & & 19 \\
\hline & $\mathrm{C}_{6} \mathrm{H}$ & $\mathrm{NO}_{2}$ & & & $\mathrm{C}_{6} \mathrm{H}$ & $\mathrm{NO}_{2}$ & $\mathrm{C}_{6} \mathrm{H}_{5}$ & \\
\hline
\end{tabular}

the unique formation of the [C-glycoside] ${ }^{+}$at $\mathrm{m} / \mathrm{z}$ 572.4412 and 572.4369 in the MS/MS analyses of the protonated molecules (GlcNAc-Chol-2) and (GlcNAcChol-3), respectively. In addition, we noticed the identical formation of the [C-glycoside $]^{+}$productions at $\mathrm{m} / \mathrm{z}$ 530.4265 and 575.4494 in the cases of $\left(\mathrm{GlcNH}_{2}-\mathrm{Chol}^{\prime}{ }^{\prime}\right)$ and (GlcNHCOCD 3 -Chol-3').

We propose that the mechanism of formation of the $[\mathrm{C} \text {-glycoside }]^{+}$product ion which occurs in the collision cell of the tandem mass spectrometer arises from the nucleophilic attack of the neutral fragment cholesta-3,5diene molecule on the activated intermediate product $[\mathrm{GlcNAc}]^{+}$oxonium ion. We postulated that the latter were formed in the collision cell by fragmentation of the precursor protonated molecule. Thus, the formation of this $\mathrm{C}$-glycoside occurs from the net result of breakage of two original covalent bonds separated by the polyethoxy chain spacer in the precursor protonated neoglycolipid. This [C-glycoside ${ }^{+}$reforms by a product ion-molecule reaction to produce a new $\mathrm{C}-1-\mathrm{C}-3^{\prime}$ covalent bond. Obviously, the formation of a C-glycoside formed by a C-1-C-5' covalent bond is not to be excluded by the same sort of mechanism, although it is improbable due to its more sterically hindered structure (see Scheme 2). Unfortunately, we do not have any chemical means to distinguish between these two pos- sible diastereomers, as the formed C-glycoside exists only briefly and cannot be isolated.

McLafferty's group has suggested that poly(ethylene/ propylene glycol) under collisionally activated dissociation using electron-capture dissociation (ECD) FTMS/MS or other energetic methods, lead to misleading rearrangements ${ }^{\circ}[10] . .^{\circ}$ They $^{\circ}$ have $^{\circ}$ also $^{\circ}$ indicated ${ }^{\circ}$ functional group migration induced by formation of alkylradical loss ions, in the mass spectra of fatty acids, using low-energy collision electron-impact MS/MS studies [11]. ${ }^{\circ}$ Longevialle $^{\circ}$ and ${ }^{\circ}$ Lefèvre $^{\circ}$ noted $^{\circ}$ that ${ }^{\circ}$ the $^{\circ}$ loss $^{\circ}$ of alkanes from ionized aliphatic alcohols, ketones, ethers and amines, during high-energy collision EI-MS/MS, happens by a 1,2-elimination involving a $\mathrm{C}-\mathrm{C}$ bond cleavage and the specific rearrangement of a hydrogen

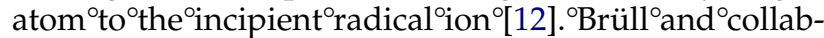
orators have observed losses of the internal residue of $1 \rightarrow 6$ substituted monosaccharide during the MS/MS analysis of underivatized and per-O-methylated trisaccharides, with either high- or low-energy CID using FAB $^{\circ}$ ionization ${ }^{\circ}[13]$.

This phenomenon of "internal residue loss", which was characterized as an "internal rearrangement" process catalyzed by a proton, was not observed in the CID-MS/MS analysis of sodium-cationized oligosaccharides $^{\circ}$ containing $^{\circ} N$-acetyl-D-glucosamine ${ }^{\circ}[14] .^{\circ}$ By 

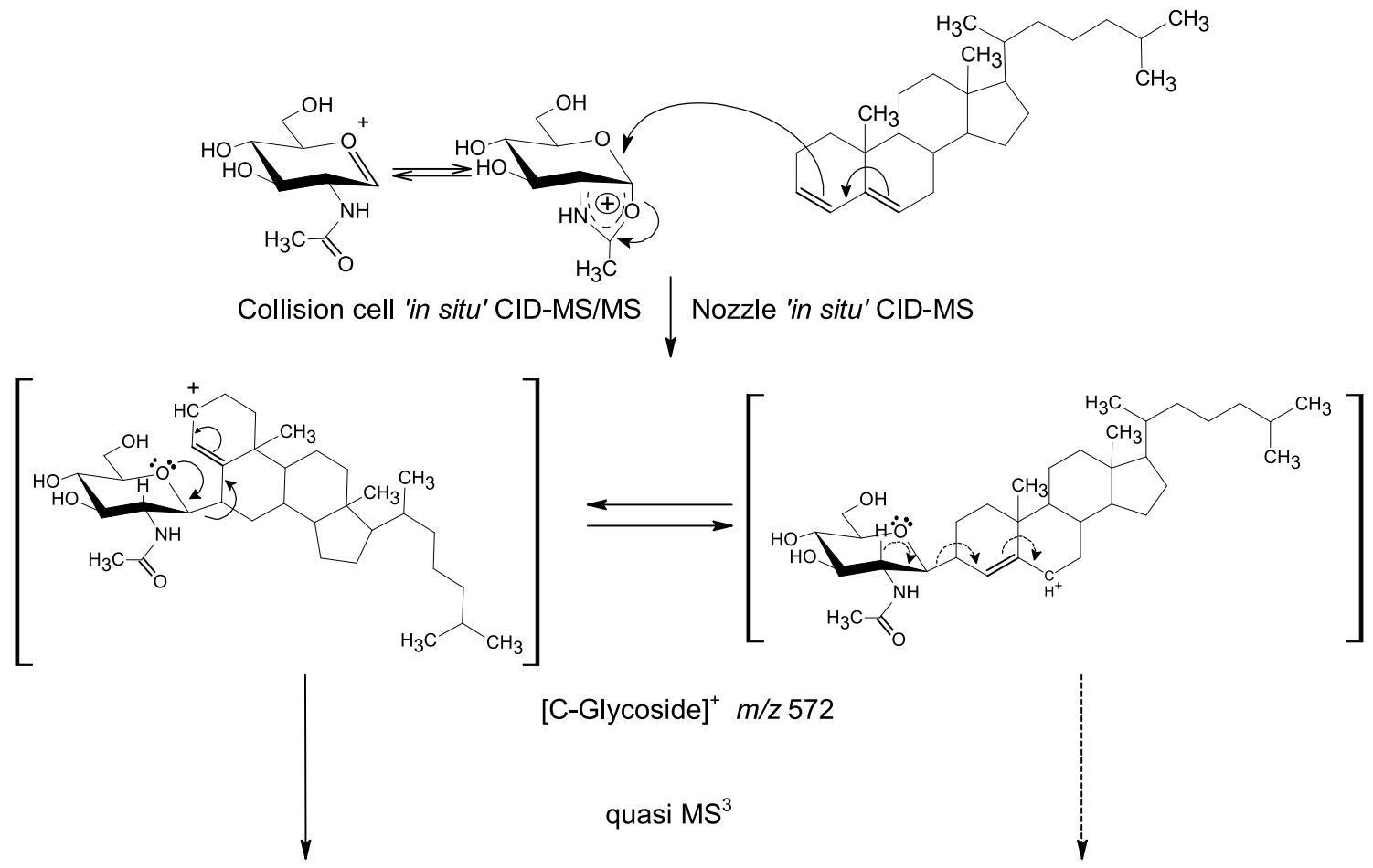

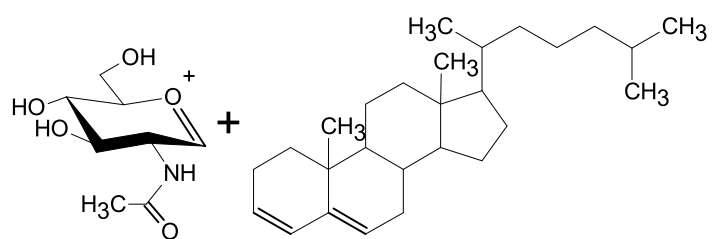

$m / z 204$

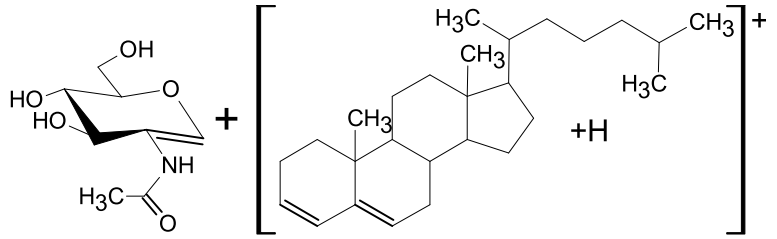

$m / z 369$

Scheme 2. Proposed pathway for the formation of the [C-glycoside $]^{+}$in the CID-MS/MS and successive dissociations to produce the characteristic product ions found in the quasi $\mathrm{MS}^{3}$ spectra.

comparison to the work of McLafferty and coworkers, Longevialle ${ }^{\circ}$ and $^{\circ}$ Lefèvre, $^{\circ}$ and $^{\circ}$ Brüll $^{\circ}$ et $^{\circ}$ al. ${ }^{\circ}\left[10^{\circ}-14\right]^{\circ},{ }^{\circ}$ our work, presented in this rationale, includes amphiphilic molecules containing sugar and cholesteryl moieties separated by a spacer, which are indeed quite different from the products used in their respective rearrangements. Also, we have employed low energy collision MS/MS using electrospray ionization, which is quite different from the studies reported above. McLafferty and coworkers established, using ${ }^{2} \mathrm{H}$ and ${ }^{13} \mathrm{C}$ labeling, that the alkyl-radical loss ions of the fatty acid occurred through the Longevialle mechanism which takes place under a 6-membered ring intermediate.

We propose that the formation of the C-glycoside is not related to intramolecular rearrangement of any specific conformation in the gas phase. Thus, it is worth mentioning that during the CID-MS/MS of the protonated neoglycolipid molecules, the glucosaminyl and the cholesteryl moieties, are both O-linked, and are separated by a variable length polyethoxy spacer arm, and any activated intermediate would necessarily include a very sterically hindered conformation involving at least a 12-membered ring for the GlcNAc-Chol-3.
Second Generation Product Ion Scan of the [C-Glycoside $]^{+}$Ion

To enhance the reaction formation of the [C-glycoside ${ }^{+}$ ion, CID in the atmospheric pressure/vacuum interface was effected with a higher declustering potential of 150 V [15]. Therefore, ${ }^{\circ}$ quasi $\mathrm{MS}^{3^{\circ}}{ }^{\circ}{ }^{\circ}$ second-generation product ion scan was achieved on the reaction intermediate [C-glycoside] $^{+}$ion at $\mathrm{m} / \mathrm{z} 572.4321$ extracted from GlcNAc-Chol-3, and afforded the protonated cholesta-3,5diene molecule product ions [cholestadiene $+\mathrm{H}^{+}$at $\mathrm{m} / \mathrm{z} 369.3533$ and the [GlcNAc] ${ }^{+}$oxonium ion at $\mathrm{m} / \mathrm{z}$ $204.0876^{\circ}$ (see ${ }^{\circ}$ Figure $^{\circ} 1 \mathrm{c}$ ). ${ }^{\circ}$ It $^{\circ}$ is ${ }^{\circ}$ reasonable ${ }^{\circ}$ to ${ }^{\circ}$ hypothesize that, in the collision cell of the tandem mass spectrometer, we have two concerted cleavages which occur simultaneously from the precursor [C-glycoside $]^{+}$ion. The first mechanism involves the elimination of the axial $\mathrm{H}-2$ hydrogen of the sugar moiety, with consecutive rupture and migration of the anomeric $\mathrm{C}-1-\mathrm{C}-3^{\prime}$ bond. This is followed by formation of the C-3'-C-4' double bond and migration of the endocyclic C $-4^{\prime}-\mathrm{C}-5^{\prime}$ double bond, to afford the protonated cholesta-3,5-diene molecule assigned as [Cholestadiene + 
$\mathrm{H}^{+} \mathrm{m} / \mathrm{z} 369.3533$ and the neutral $N$-acetyl-2-deoxy-Dglucal. The second mechanism suggests the participation of the lone pair of electrons on the sugar ring oxygen to afford the stable 1,2-oxonium ion [GlcNAc] ${ }^{+}$ at $\mathrm{m} / \mathrm{z} 204.0876$ (which is in equilibrium with the 1,2-cyclic oxonium ion), with identical rupture of the anomeric $\mathrm{C}-1-\mathrm{C}-3^{\prime}$ bond and migration of the double bonds, to produce the neutral choles-3,5-diene molecule. Please note that a similar mechanism can be applied to the C-1-C-5' C-glycoside diastereomer, and that the dissociation of the [C-glycoside $]^{+}$ion is not catalyzed by a proton. The quasi $\mathrm{MS}^{3}$ of the ion at $\mathrm{m} / \mathrm{z}$ $575.4532^{\circ}$ is $^{\circ}$ shown $^{\circ}$ in $^{\circ}{ }^{\circ}$ igure ${ }^{\circ} 1 \mathrm{C}^{\circ}$. It ${ }^{\circ}$ is ${ }^{\circ}$ interesting ${ }^{\circ}$ to ${ }^{\circ}$ note that quasi $\mathrm{MS}^{3}$ of all the [C-glycoside $]^{+}$ions obtained from the series GlcNAc-Chol-1 and GlcNAc-Chol-4 gave identical results. Please note that separate quasi $\mathrm{MS}^{3}$ analyses with increasing $\mathrm{CE}$ values showed further fragmentation of the $[\mathrm{C} \text {-glycoside }]^{+}$ions. The proposed fragmentation routes of the tandem mass spectrum of the [C-glycoside] ${ }^{+}$ion at $\mathrm{m} / \mathrm{z} 572.4321$ are presented in Scheme 2.

We have prepared a new series of compounds in which the cholesterol and other lipophilic and carbohydrate ( $\mathrm{N}$-acetyl-D-glucosamine and $\mathrm{N}$-acetyl-D-lactosamine) moieties are separated by nonlabeled and deuterated analogs of the oligoethylene glycol spacer. The syntheses and the ESI-MS and ESI-MS/MS of this series of novel neoglycolipids will be reported in a full paper when completed.

\section{Conclusions}

The aim of this communication was to define the ESI-MS fragmentation routes of this novel series of synthetic neoglycolipids of SG molecules by electrospray ionization mass spectrometry. Low-energy CID-MS/MS analysis provided distinct characteristic fingerprint ions, which confirmed the conventional fragmentations. In addition, we elucidated, during the CID-MS/MS, the proper identity of the [C-glycoside $]^{+}$ion.

To our knowledge, there has not been any documented research work published concerning the "in situ" C-glycosidation product formed from the ESI-MS analysis of an O-linked amphiphilic neoglycolipid reaction occurring in the gas phase during electrospray ionization, or any other ionization methods. Such a complicated and unusual C-glycosidation occurring during ESI-MS and MS/MS should be quite interesting to synthetic carbohydrate chemists considering that, of all synthetic (or natural) glycosylations, the occurrence of a C-glycosylation is, by far, more difficult than that of normal ${ }^{\circ} \mathrm{O}$ - or $\mathrm{N}$-glycosylation ${ }^{\circ}$ reaction $^{\circ}\left[7-9,{ }^{\circ} 16\right] .^{\circ}$ This type of C-glycoside formation augurs well for the use of the electrospray ionization source and the collision cell of the tandem mass spectrometer as a potential chemical reactor which, hopefully, will be exploited in biological organic mass spectrometry.

\section{Acknowledgments}

JB acknowledges the financial support of the Natural Sciences and Engineering Research Council of Canada for a Discovery Grant, and Applied Biosystems for generously providing extra ionization sources necessary for ESI-QqTOF-MS experiments.

\section{References}

1. Kemoun, R.; Gelhausen, M.; Besson, F.; Lafont, D.; Buchet, R.; Boullanger, P.; Roux, B. Interactions of Egg Yolk Phosphatidylcholine with Cholesteryl Polyethoxy Neoglycolipids Containing N-Acetyl-D-Glucosamine. J .Mol. Struct. 1998, 10, 395404.

2. Lafont, D.; Boullanger, P.; Chierici, S.; Gelhausen, M.; Roux, B. Cholesteryl Polyethoxyethylene Glycols as D-Glucosamine Anchors into Phospholipid Bilayers. New J. Chem. 1996, 20, 1093-1101.

3. Duffels, A.; Green, L. G.; Ley, S. V.; Miller, A. D. Synthesis of High-Mannose Type Neoglycolipids: Active Targeting of Liposomes to Macrophages in Gene Therapy. Chemistry 2000, 6, $1416-1430$.

4. Xu, Z.; Jayaseharan, J.; Marchant, R. E. Synthesis and Characterization of Oligomaltose-Grafted Lipids with Application to Liposomes. J. Colloid Interface Sci. 2002, 252, 57-65.

5. Perouzel, E.; Jorgensen, M. R.; Keller, M.; Miller, A. D. Synthesis and Formulation of Neoglycolipids for the Functionalization of Liposomes and Lipoplexes. Bioconjug. Chem. 2003, 14, 884-898.

6. El Aneed, A. Current Strategies in Cancer Gene Therapy. J. Control Release 2004, 94, 1-14.

7. Hanessian, S.; Banoub, J. Innovations in Synthetic Carbohydrate Chemistry-Practical and Conceptual Approaches to Glycoside Synthesis. A. C. S. Symp. Ser. 1976, 39, 36-63.

8. Banoub, J.; Boullanger, P.; Lafont, D. Synthesis of Oligosaccharides of 2-Amino-2-Deoxy Sugars. Chem. Rev. 1992, 92(6), 1167-1195.

9. Hanessian. S.; Luo, B. Stereocontrolled Glycosyl Transfer Reactions with Unprotected Glycosyl Donors. Chem. Rev. 2000, 100(12), 4443-4464.

10. Vidasky, I.; Chorush, R. A.; Longevialle, P.; McLafferty, F. W. Funtional Group Migration in Ionized Long-Chain Compounds. J. Am. Chem. Soc. 1994, 116, 5865-5872.

11. Cerda, B. A.; Horn, D. H. M.; Breuker, K.; McLafferty, F. W. Sequencing of Specific Copolymer Oligomers by Electron Capture-Dissociaton Mass Spectrometry. J. Am. Chem. Soc. 2002, 124, 9287-9291.

12. Longevialle, P.; Lefèvre, O.; Mollova, N.; Bouchoux, G. Further Arguments Concerning a 'Rotational Effect' in the Unimolecular Fragmentations of Organic Ions in the Gas Phase. Rapid Commun. Mass Spectrom. 1998, 12, 57-60.

13. Brüll, L. P.; Heerma, W.; Thomas-Oates, J. E.; Haverkamp, J.; Kovácik, V.; Kovác, P. Loss of Internal $1 \rightarrow 6$ Substituted Monosaccharide Residues and Per-O- Methylated Trisaccharides. J. Am. Soc. Mass Spectrom. 1997, 8, 43-49.

14. Brüll, L. P.; Kovácik, V.; Thomas-Oates, J. E.; Heerma, W.; Haverkamp, J. Sodium-Cationized Oligosaccharides Do Not Appear to Undergo "Internal Residue Loss" Rearrangement Processes on Tandem Mass Spectrometry. Rapid Commun. Mass Spectrom. 1998, 12, 1520-1532.

15. Allen, M. H.; Vestal, M. L. Design and Performance of a Novel Electrospray Interface. J. Am. Soc. Mass Spectrom. 1992, 3, $18-26$.

16. Beau, J. M.; Gallagher, T. Nucleophilic C-Glycosyl Donors for C-Glycoside Synthesis. Topics in Current Chemistry 1997, 187, $1-54$. 